This item was submitted to Loughborough's Research Repository by the author.

Items in Figshare are protected by copyright, with all rights reserved, unless otherwise indicated.

\title{
An experimental investigation into DEF dosing strategies for heavy duty vehicle applications
}

PLEASE CITE THE PUBLISHED VERSION

http://dx.doi.org/10.4271/2015-01-1028

PUBLISHER

(C) SAE International

VERSION

VoR (Version of Record)

LICENCE

CC BY-NC-ND 4.0

\section{REPOSITORY RECORD}

Gaynor, Paul D., Benjamin A. Reid, Graham K. Hargrave, Thomas O. Lockyer, and Jonathan Wilson. 2019. "An Experimental Investigation into DEF Dosing Strategies for Heavy Duty Vehicle Applications". figshare. https://hdl.handle.net/2134/23257. 


\title{
An Experimental Investigation into DEF Dosing Strategies for Heavy Duty Vehicle Applications
}

\author{
Paul Gaynor, Benjamin Reid, Graham Hargrave, Thomas Lockyer, and Jonathan Wilson \\ Loughborough University
}

\begin{abstract}
In recent years urea selective catalytic reduction (SCR) has become the principal method of NOx abatement within heavy duty (HD) diesel exhaust systems; however, with upcoming applications demanding NOx reduction efficiencies of above $96 \%$ on engines producing upwards of $10 \mathrm{~g} \cdot \mathrm{kWh}^{-1} \mathrm{NOx}$, future diesel exhaust fluid (DEF) dosing systems will be required to operate stably at significantly increased dosing rates.

Developing a dosing system capable of meeting the increased performance requirements demands an improved understanding of how DEF sprays interact with changing exhaust flows. This study has investigated four production systems representing a diverse range of dosing strategies in order to determine how performance is influenced by spray structure and identify promising strategies for further development.

The construction of an optically accessible hot-air flow rig has enabled visualisation of DEF injection into flows representative of HD diesel exhaust conditions. High-speed and laser sheet imaging have been applied to capture the injection event and analyse spray development within the flows.

Results from ambient shadowgraphy show the extent of variation in spray structure that exists between the systems; further quantified with droplet size distribution data collected using phase Doppler interferometry (PDI). Imaging within the exhaust section indicates that the structure of a spray has a significant impact on droplet entrainment within the flow, in turn affecting the level of spray-wall impingement seen. This suggests knowledge of dosing strategy will be critical for optimal system design and enabling near future dosing rate demands to be met.
\end{abstract}

CITATION: Gaynor, P., Reid, B., Hargrave, G., Lockyer, T. et al., "An Experimental Investigation into DEF Dosing Strategies for Heavy Duty Vehicle Applications," SAE Int. J. Engines 8(3):2015, doi:10.4271/2015-01-1028.

\section{INTRODUCTION}

The treatment of engine out NOx using selective catalytic reduction has been an area of research interest for over a decade, during which time the technology has been demonstrated as an effective method of reducing tailpipe NOx and widely adopted for both on- and offhighway applications. There currently exists detailed treatment of the fundamental reaction schemes of the SCR process, from ideal decomposition to proposed pathways that lead to undesirable reaction by-products often found as deposits within exhaust systems.

The fundamental principal of the technology is the promotion of reactions between engine out $\mathrm{NOx}$ and ammonia $\left(\mathrm{NH}_{3}\right)$ in the presence of oxygen [1]. The reaction products, nitrogen and water, are then safely emitted at the tailpipe. However, issues with safe on-board storage of ammonia have led to the use of precursors: less hazardous substances such as urea, from which ammonia can be generated [2]. Diesel exhaust fluid (DEF), a mixture of $32.5 \%$ urea and $67.5 \%$ de-ionised water, is the most widely used of these, with a now mature supply infrastructure established. As DEF is liquid at atmospheric conditions it is injected into the exhaust gas, where first the water content is evaporated off before the urea thermally decomposes to ammonia and isocyanic acid (HNCO). Isocyanic acid is stable in the gas phase, but will hydrolyse to carbon dioxide $\left(\mathrm{CO}_{2}\right)$ and ammonia on surfaces within the exhaust system or the SCR catalyst. However, in reality the formation of decomposition by-products through alternative reaction paths is often seen, with deposit formation from injected urea widely reported within SCR studies $[\underline{3}, \underline{4}, \underline{5}, \underline{6}]$. A detailed study of the decomposition of urea has shown that the by-products present during decomposition at different temperatures include biuret, cyanuric acid, ammelide, ammeline and melamine [7]. A large number of desirable and undesirable reactions have been proposed [ $\underline{8}$ ], with reactions involving the intermediate HNCO attributed to producing common by-products [9] , yet despite this knowledge operating free of deposits still poses the most significant challenge for urea SCR systems. 
Deposit formation is often seen to occur at low exhaust temperatures, with cooling by the DEF spray causing internal surfaces to fall below a critical temperature and become wetted [ $\underline{4}$ ]. To prevent excessive cooling, maps of maximum allowable dosing rate can be generated experimentally; limiting the DEF dose given monitored exhaust flow conditions. This approach enables stable operation of urea SCR; however, the NOx reduction of such a system is constrained by the ability of the dosing system to operate without forming deposits. Therefore, to maximise the NOx reduction efficiency that can be achieved approaches to increase this maximum stable dosing rate must be developed.

One reported approach is to improve the atomisation of the DEF spray, reducing droplet residence time and therefore decreasing the quantity of spray impacting on and cooling internal surfaces.

Alternative routes to a finely atomised spray can be taken, with high pressure and air-assisted injectors both reported to show reduced droplet size $[10, \underline{11}]$. The approach is supported by modelling results which have suggested that droplet evaporation time can be reduced significantly when atomised to $50 \mu \mathrm{m}[12]$, although this alone cannot guarantee spray-wall impingement is avoided. With single fluid injectors capable of atomising droplets to below $100 \mu \mathrm{m}$, a move towards more advanced single fluid injectors has been reported as a current trend in the industry [13] .

The use of mixing devices as an additional component coupled to the dosing system is another strategy to improve system performance now commonplace within SCR systems: providing hot-surfaces within the flow to break-up larger droplets and promote mixing to increase ammonia uniformity. Much work has been done on investigating the design of mixing devices $[\underline{14}, \underline{15}, \underline{16}]$, with experimental and simulation results suggesting that performance gains are achievable when a holistic design approach is taken [11]. Detailed knowledge of the spray structure and exhaust geometry are therefore critical when developing an optimised mixing device. Similar approaches, such as dosing directly onto a hydrolysis catalyst [17], have been proposed, although such systems still require an understanding of spray behaviour within the gas flow to ensure an even coverage across the catalyst face is achieved.

The work dedicated to developing high efficiency urea SCR has so far culminated in systems reportedly capable of NOx reduction efficiencies of approaching $96 \%[\underline{6}, \underline{18}]$. In Europe, tailpipe out NOx limits of $0.4 \mathrm{~g} \cdot \mathrm{kWh}^{-1}$ will require NOx reduction efficiencies approaching $98 \%$ given the engine out NOx levels upwards of 10 $\mathrm{g} \cdot \mathrm{kWh}^{-1}$ possible from proposed high efficiency combustion configurations [19]. Therefore, next generation systems will be required to operate at increased efficiency with DEF dosing loads exceeding current operation while remaining deposit free.

Meeting required performance levels presents a difficult challenge for aftertreatment designers, and a fundamental understanding of the interactions between DEF sprays and exhaust flows is now critical to maximise the NOx reduction achievable in next generation systems. With a broad range of urea dosing systems commercially available it appears likely that the hardware to meet the challenge exists; however, as yet a clear demonstration of the effect that injection strategy can have on spray development within realistic hot-flow conditions has not been seen.
This study has identified how the structure of a spray affects droplet interaction with bulk exhaust flows, and in turn discusses features of a dosing strategy that could enable stable performance as higher dosing rates are demanded. The study has not set out to assess or rank the dosing systems that have been investigated and no judgement on the quality of the hardware provided has been made.

\section{EXPERIMENTAL SET-UP}

Experimental work within this study has focused on analysing the spray structure of four commercial SCR dosing systems, each of which possess distinct design features influencing different operation strategies. Systems were first set-up and tested following manufactures guidelines in order to identify operating principles, and enable a characterisation study of the spray produced in ambient conditions to be performed. Each system was then installed on a hot-flow test facility to allow observation of the injection events in conditions representative of real world application.

\section{Commercial Dosing System Overview}

The four dosing systems procured for this study were commercially available production systems, and therefore representative of urea SCR dosing system technology at the time of testing. Key features of system operation for each of the four units are summarised in Table 1. The breadth of injector hardware available gives an indication of the importance of understanding how changing injection strategy can affect the performance of a system.

Table 1. Summary of dosing system key features

\begin{tabular}{|l|c|c|c|c|}
\hline System & A & B & C & D \\
\hline $\begin{array}{l}\text { Injection } \\
\text { fluid }\end{array}$ & Air-assist & Single fluid & Single fluid & Air-assist \\
\hline $\begin{array}{l}\text { Dose } \\
\text { metering }\end{array}$ & $\begin{array}{l}\text { Frequency } \\
\text { modulated }\end{array}$ & $\begin{array}{c}\text { Pulse-width } \\
\text { modulated } \\
(1 \mathrm{~Hz})\end{array}$ & $\begin{array}{c}\text { Pulse-width } \\
\text { modulated } \\
(1 \mathrm{~Hz})\end{array}$ & $\begin{array}{c}\text { Continuous } \\
\text { (at point of } \\
\text { injection) }\end{array}$ \\
\hline $\begin{array}{l}\text { Metering } \\
\text { control }\end{array}$ & At pump & $\begin{array}{c}\text { Injector head } \\
\text { (solenoid) }\end{array}$ & $\begin{array}{c}\text { Injector head } \\
\text { (solenoid) }\end{array}$ & At pump \\
\hline $\begin{array}{l}\text { Injector } \\
\text { location }\end{array}$ & Wall & Wall & Wall & Centre-line \\
\hline $\begin{array}{l}\text { Number of } \\
\text { orifices }\end{array}$ & $\begin{array}{c}2 \\
\text { (Concentric) }\end{array}$ & 3 & 1 & $\begin{array}{c}4 \\
\text { (Radial) }\end{array}$ \\
\hline
\end{tabular}

Commercial DEF was used as the injection fluid in all testing performed within this study. Where compressed air was not generated by the dosing system it was supplied from compressed air lines within the laboratory at $5 \mathrm{bar}(\mathrm{g})$. During testing each system was controlled via control area network (CAN) bus communication enabling manual specification of dosing rates.

\section{Hot-Flow Test Facility}

To generate hot gas flows representative of a HD diesel exhaust a bespoke facility was designed and built within the Optical Engineering Laboratories at Loughborough University. The facility comprises of two enclosed optical test benches, each supplied with high temperature air-flows for parallel study and development of urea SCR dosing systems. To enable fundamental study of spray-flow interactions the facility was designed to operate with independent control of gas flow rate and temperature, achieved by artificially generating and heating an air flow. Twin $30 \mathrm{~kW}$ air blowers supply air at flow rates of up to $900 \mathrm{~kg} \cdot \mathrm{hr}^{-1}$ to each of the rigs, which is heated to up to $600{ }^{\circ} \mathrm{C}$ with $120 \mathrm{~kW}$ in-line electric heaters. As the bulk flow 
does not contain combustion products, no SCR reactions take place within the facility. Therefore an ammonia slip catalyst (ASC) was installed downstream of the test section to manage emission of ammonia produced from DEF decomposition. All results presented in this paper have been collected using dry air as the hot gas.

Due to the nature of the experimental work, all testing was performed within interlocked enclosures, ensuring the optical benches are Class 1 systems to minimise the risk of exposure to laser emissions. The insulated pipework installed within the enclosed cabinets is shown in Figure 1, illustrating the configuration of the test section used to collect the data presented within this study.

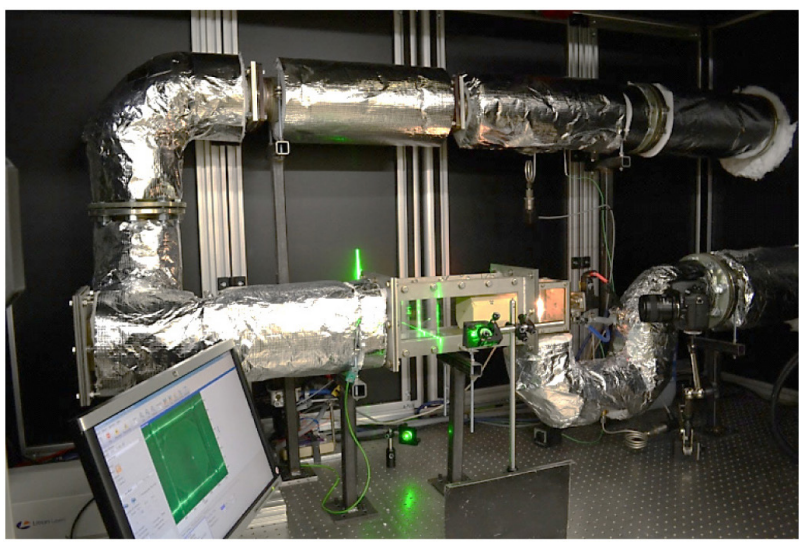

Figure 1. Hot-flow pipework geometry and optical section within laser cabinet

\section{Flow Control}

Heater controllers were used to set flow temperatures at the heater outlet, with the temperature at the rig inlet, measured with a K-type thermocouple, used to monitor the test section temperature. The air mass flow rate was set using valve control on main and by-pass flow lines and measured using an insertion probe thermal mass flow meter. Temperatures and pressures across the test section were also monitored and logged during experimental work. A schematic of facility components relevant to this study is included in Figure 2.

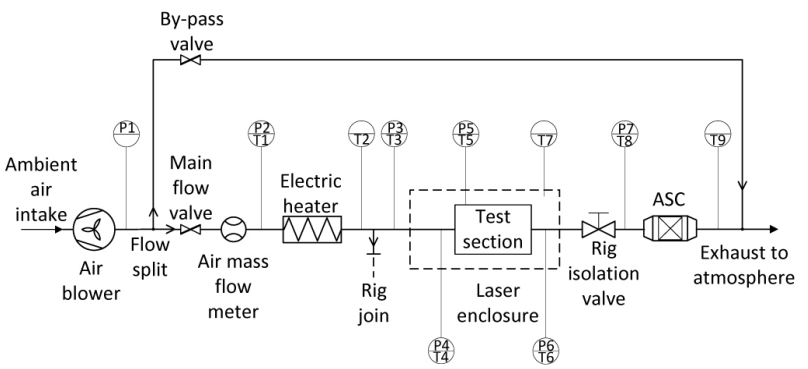

Figure 2. Schematic of hot-flow test facility showing sensor locations

\section{Test Section Geometry}

Injection systems were mounted on a sharp $90^{\circ}$ bend to imitate s-bend and flow-hood injection configurations. The only exception to this was the centre-line injector, which was mounted immediately downstream of the bend in the straight optical pipe section.

A square profile optical pipe section, $90 \times 90 \mathrm{~mm}$ in dimension, was designed incorporating quartz windows to give visual access at the point of injection and along the central axis of the injection pipe. Figure 3 illustrates the test section geometry, showing the flow path, injector locations and optical access.

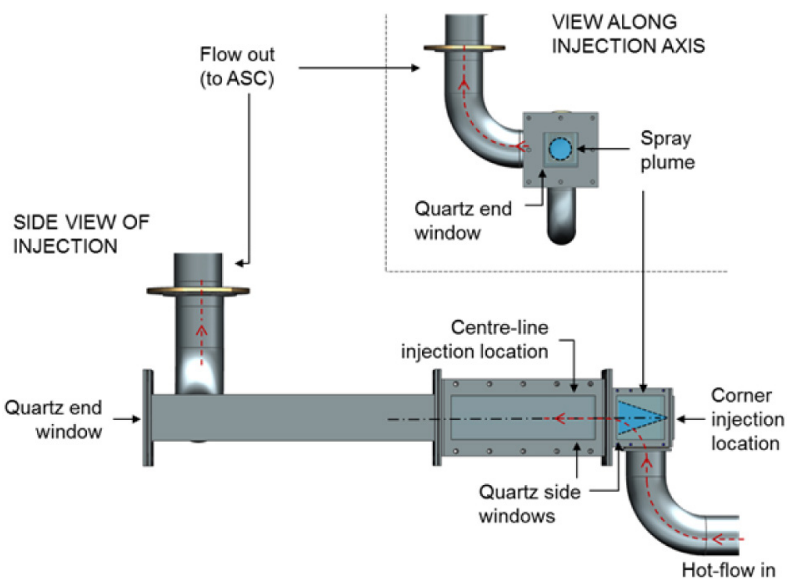

Figure 3. Test section set-up showing optical access at the point of injection and along the injection axis

Side and end quartz windows enable the application of shadowgraphy and laser sheet imaging (LSI) to visualise the spray within the flow up to $400 \mathrm{~mm}$ downstream of the point of injection. The experimental set-up of all hot-flow testing is illustrated in Figure 4, including the camera layouts and location of laser sheets.

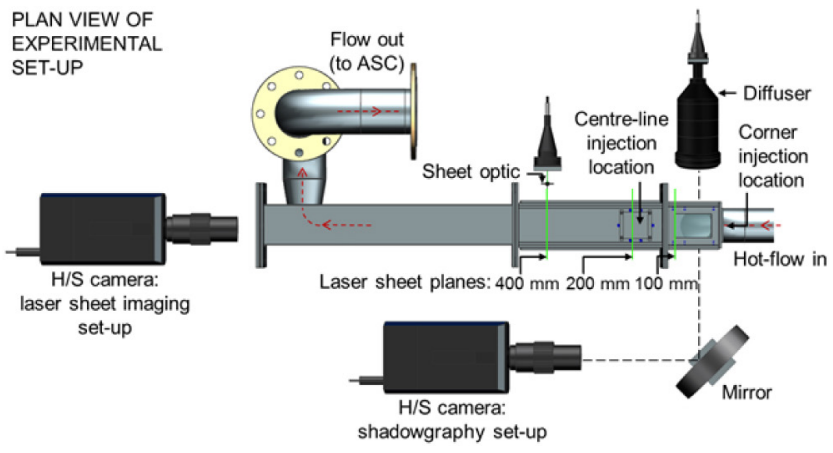

Figure 4. Plan view of optical test section with set-up of imaging tools for shadowgraphy and laser sheet imaging within a hot-flow

\section{Optical Diagnostics}

A number of optical diagnostic techniques were used to perform spray analysis within this study. Imaging techniques were used in both ambient and hot-flow conditions, with quantitative phase Doppler interferometry (PDI) data for spray characterisation collected only in ambient conditions.

\section{Spray Visualisation}

High-speed shadowgraphy imaging was the primary method of spray visualisation used within this study. An Imager pro HS 4M camera supplied by LaVision UK Ltd. was used to capture the spray formation at a frame rate of $1 \mathrm{kHz}$ and resolution of $2016 \times 2016$ pixels. An imaged region of approximately $120 \times 120 \mathrm{~mm}$ was captured using a $105 \mathrm{~mm}$ Nikkor lens, giving a scale factor of 0.058 $\mathrm{mm} /$ pixel. An aperture setting of $f / 11$ was used to provide adequate depth of field when capturing injection events. Start and end of injection events were manually identified within the series of stored images. Fluorescent light produced by expanding an Nd:YLF (527 $\mathrm{nm}$ ) laser beam into a Rhodamine $6 \mathrm{G}$ dye screen was used to back illuminate all shadowgraphy images. A far field microscope was used to provide more detail on spray break-up at the nozzle. 
Laser sheet imaging, another visualisation technique, was used during testing to capture droplet distributions within the spray cross sections. Plano-convex cylinder optics were used to generate 2-dimensional laser sheets aligned perpendicular to the spray axis, enabling the spray footprint to be captured at various distances from the nozzle.

\section{Image Processing}

Slight variations in illumination intensity in shadowgraphy images were corrected by capturing a background image of the illumination source at the beginning of each image series and subtracting it from the experimental images. Intensity thresholds dictating image contrast were selected to ensure the spray structure is clearly visible in each image series. The processing has been kept consistent across data sets; however, slight adjustment was required between each spray.

Processing image sets to produce a composite image was also performed within the body of work. Typically an RMS average of a series of LSI images was taken in order to represent an injection event with a single image. Such images will be seen in analysis of spray cross sections in ambient and hot-flow conditions reported in the results section.

\section{Phase Doppler Interferometry}

Point measurements of droplet size and velocity were obtained in ambient conditions using phase Doppler interferometry. An Artium Technologies PDI-200 system capable of measurements in twodimensions was set-up to collect droplet data at a point until either 10000 droplets had been detected or 20 seconds had passed. As droplet size and velocity measurements are made at the waist of interfering beams the system was traversed through the sprays in planes orthogonal to the spray axis, characterising the sprays at 50 , 100 and $200 \mathrm{~mm}$ from the nozzle.

\section{Experimental Test Conditions}

Detailed characterisation of the four sprays was performed in ambient conditions. During PDI measurements sprays were directed into an extraction system in order to prevent buoyant droplets re-entering the measurement volume.

Table 2. Summary of flow conditions and dosing rates used during hot-flow injection event observation

\begin{tabular}{|c|c|c|c|}
\hline Test point & $\begin{array}{c}\text { Mass flow rate } \\
\left(\mathbf{k g} \cdot \mathbf{h r} \mathbf{r}^{-1}\right)\end{array}$ & $\begin{array}{c}\text { Flow } \\
\text { temperature }\left({ }^{\circ} \mathbf{C}\right)\end{array}$ & $\begin{array}{c}\text { Dosing rate } \\
\left(\mathbf{g} \cdot \mathbf{h r}^{-1}\right)\end{array}$ \\
\hline 1 & 200 & 200 & 100 \\
\hline 2 & 200 & 350 & 400 \\
\hline 3 & 900 & 200 & 900 \\
\hline 4 & 900 & 350 & 2000 \\
\hline
\end{tabular}

Observation of injection events within hot-air flows was performed at four conditions for each system. The test points, given in Table 2 , were selected to be representative of conditions seen in application and illustrate the effect that flow rate and temperature have on spray propagation within a flow. Dosing rates used during testing were based on maximum deposit free dosing rates achievable at each flow condition at the time of testing.

\section{RESULTS AND DISCUSSION}

Detailed characterisation of each spray including visualisation of spray structure and cross section, and quantitative droplet size distribution data will first be presented with discussion of the dosing system operation in ambient conditions. Attention is given to the consistency of the spray produced during an injection event and across the range of system dosing rates in order to identify any features of the spray likely to contribute to unstable performance during application. Visualisation of each spray within hot-gas flows will then be presented to illustrate DEF spray development within real-world application conditions and link spray-flow interactions with spray characterisation data.

\section{Spray Structures in Ambient Conditions}

Images typical of the fully developed spray produced by each system are presented in Figure 5. From these images alone the extent of variation in spray structure between production systems can be seen. The spray plumes produced by the air-assisted systems A and D appear well atomised but within tighter cones than the single fluid sprays of $\mathrm{B}$ and $\mathrm{C}$. The three distinct jets that can be discerned in spray B correlate to the number of orifices of the system, and are seen to atomise into a coarse, yet well dispersed spray. Spray $\mathrm{C}$ appears similar to the air-atomised spray of A in structure, yet the pressure swirl injector atomises the DEF dose without a second fluid. A fundamentally different dosing strategy is seen in the spray produced by system $\mathrm{D}$, whereby a mixture of DEF and compressed air is radially injected through four orifices offering a wide dispersion of the dose.
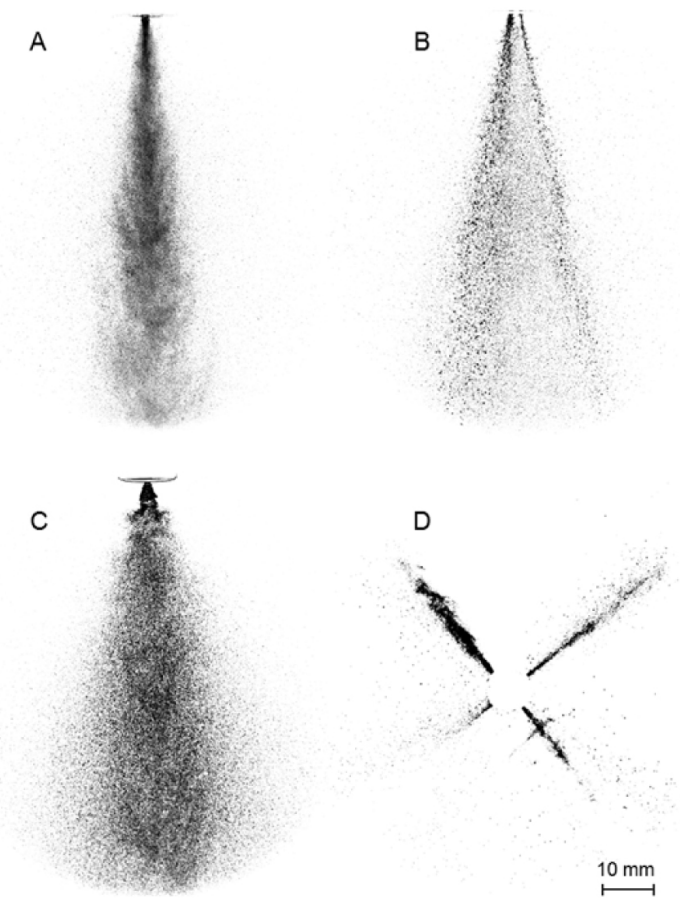

Figure 5. Shadowgraphy images showing variation in spray structure between four production systems: DEF dosing at $1000 \mathrm{~g} \cdot \mathrm{hr}^{-1}$ in ambient conditions. 


\section{Consistency across Dosing Event}

High-speed imaging of the injection events shows marked differences in the development and termination of spray events as well as the duration of injection for each system. Solenoid actuation within the injector heads of the single fluid dosing systems, B and C, is seen to result in well-defined spray events. High-speed images of the injection event of sprays A and D show slower spray development and terminations phases, which is likely to be a result of DEF metering upstream of the nozzle. Despite this spray A is seen to dose with reasonable consistency across the event due to DEF-air mixing occurring as both fluids exit the nozzle. The most intermittent spray event seen is that produced by system D, which meters DEF at the pump and mixes the fluid with compressed air within the dosing line. It is likely that the chaotic mixing between the metering point and the nozzle caused the sporadic injection events seen.

The results visible within image series have been summarised in the form of Figure 6, which plots the normalised spray quantity detected as dark pixels within a shadowgraphy image frame - over the duration of an injection event. In terms of predictability it is clear that dose metering at the point of injection is effective at delivering defined injection events; however, fluctuations in pump metered sprays occur at high temporal frequencies, therefore any impact on SCR system stability may be limited.

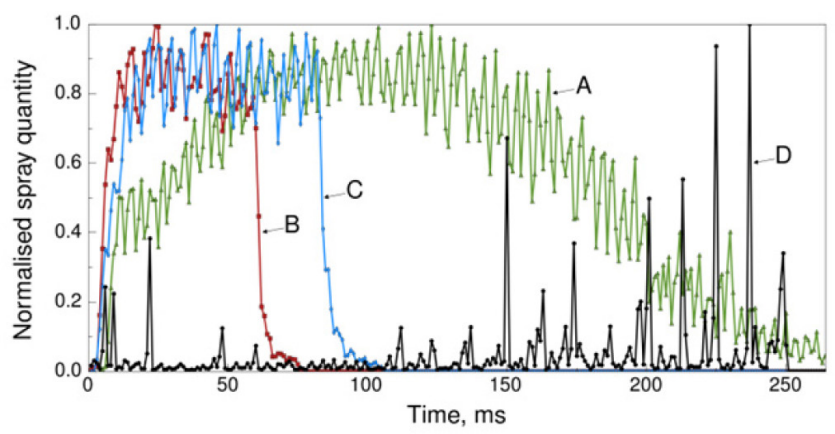

Figure 6. Plot of spray quantity throughout dosing event at $400 \mathrm{~g} \cdot \mathrm{hr}^{-1} \mathrm{DEF}$ - derived from pixel count of shadowgraphy images

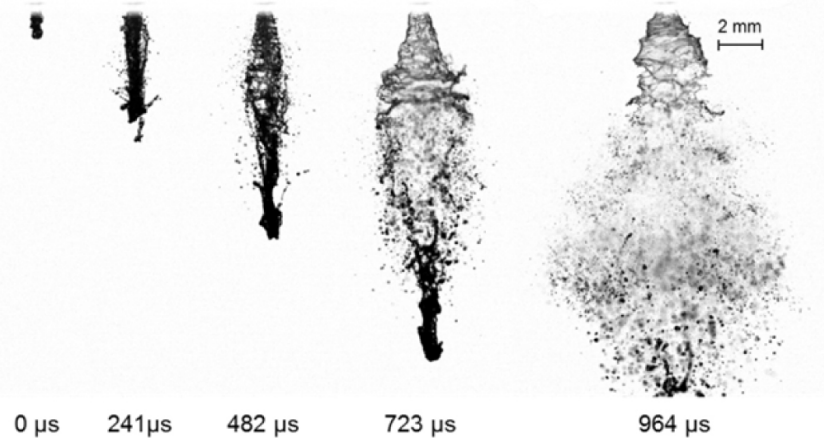

Figure 7. Time series shadowgraphy images of spray $\mathrm{C}$ at the start of injection event - depicting evidence of a slug of fluid

Qualitative data from high-speed imaging also reveals features of the injection event that cannot be seen in real time. Study of the spray break-up at the start of injection of system C, seen in Figure 7, shows a failure to atomise some of the dose, leading to a slug of fluid being injected with each event, i.e. at $1 \mathrm{~Hz}$. Although this is a known feature of pressure-swirl injection events it is unlikely that quantitative analysis such as PDI would detect the phenomenon, and possible it may not be captured in models of the spray, yet it presents the potential to affect deposit formation, and so should be considered during system design.

\section{Consistency across Dosing Rates}

Variation in spray structure as the dosing rate increases is also considered of interest as demands on dosing rates are increasing. High-speed images of the sprays produced at varying dosing rates suggest that making the assumption of a consistent spray structure may be false, a result which may lead to misguided system design.

Figure 8 illustrates the spray structure across the dosing range of system B. The spray structure can be seen to be very similar at low and high dosing rates, which can be expected as pulse duration is used to meter the spray. A similar consistency across the range of dosing rates was displayed by system $\mathrm{C}$, which is also pulse-width modulated.
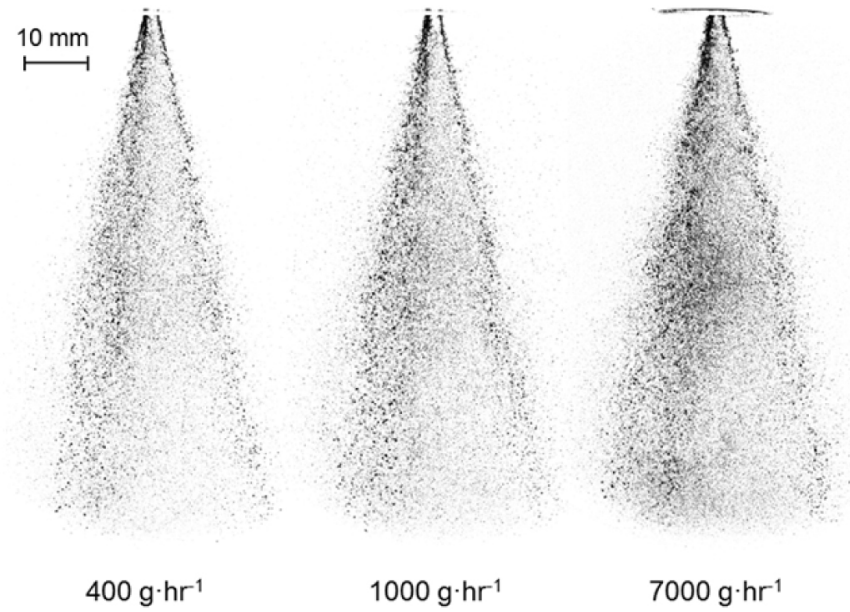

Figure 8. Shadowgraphy images of the structure of spray B across the working range of DEF dosing rates

In contrast, Figure 9 indicates a striking variation in the density of spray A across the working range of the system. It is also evident that at high dosing rates visibly larger droplets are present within the spray, suggesting the injection fluid is not atomised as effectively. As the flow rate of air is constant the reduction in spray atomisation could be attributed to the volumetric ratio of DEF to air being injected, which at high dosing rates is reduced from approximately $1: 10000$ to $1: 500$.

The effect that an increase in the volumetric DEF:air ratio has on spray quality is seen most severely in the spray produced by system $\mathrm{D}$ which has been seen to intermittently inject poorly atomised liquid jets, shown in Figure 10, at dosing rates of above $3000 \mathrm{~g} \cdot \mathrm{hr}^{-1} \mathrm{DEF}$.

Observation of the changes in spray quality can be further supported using quantitative droplet size data collected with PDI measurements. A plot of measured SMD values at a plane $100 \mathrm{~mm}$ from the nozzle is given in Figure 11, indicating how the average droplet diameter changes with DEF dosing rate for each of the four systems. The most obvious result of PDI measurements can be seen in the large gap 
between the SMD of spray B when compared to the other systems, which correlates with the visualisations of the spray structure seen previously in Figure 5. The effectiveness of air-assisted atomisation is clearly illustrated by the data, as is the ability of the pressure-swirl injector to produce a fine spray. Also clear is a trend of increasing droplet sizes with dosing rates, particularly for the air-assisted systems. Relative to the lowest SMD achieved the air-assisted systems, A and D, saw an increase of $113 \%$ and $141 \%$ in SMD across their working dosing range respectively. The single fluid systems saw significantly smaller relative differences between the extreme SMD values, with an increase of $15.3 \%$ for spray B and $29.1 \%$ for spray $\mathrm{C}$.

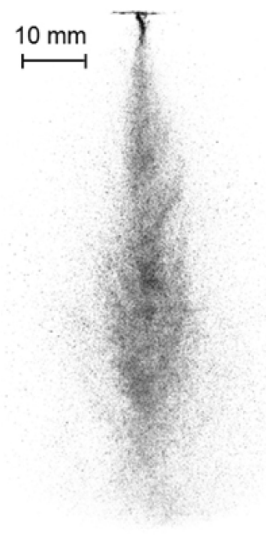

$400 \mathrm{~g} \cdot \mathrm{hr}^{-1}$

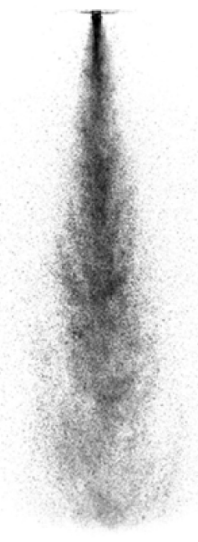

$1000 \mathrm{~g} \cdot \mathrm{hr}^{-1}$

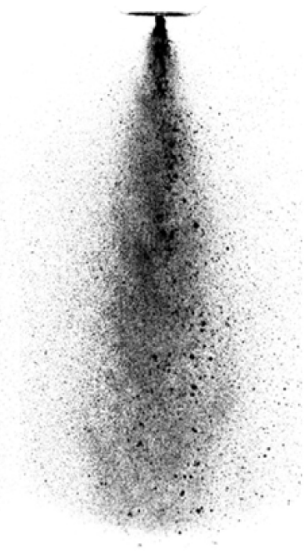

$7000 \mathrm{~g} \cdot \mathrm{hr}^{-1}$
Figure 9. Shadowgraphy images of the structure of spray A across the working range of DEF dosing rates
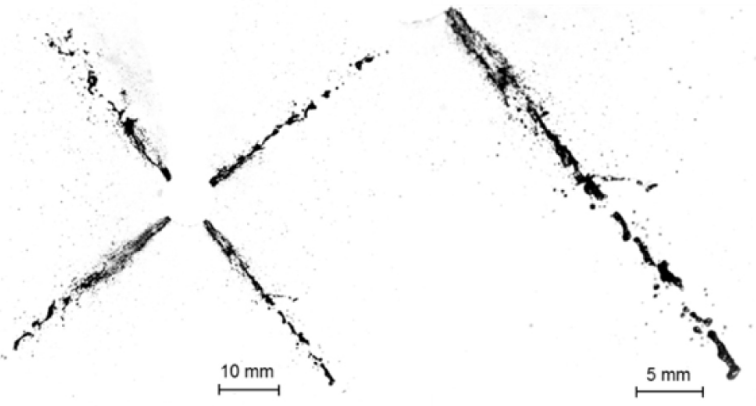

Figure 10. Shadowgraphy image of spray D at $7000 \mathrm{~g} \cdot \mathrm{hr}^{-1} \mathrm{DEF}$ dosing rate, showing poor spray atomisation at high volumetric DEF:air ratios

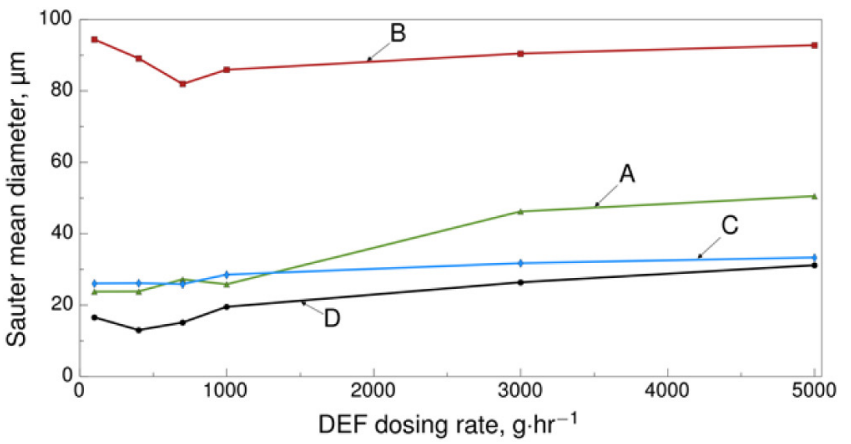

Figure 11. Spray SMD values at a plane $100 \mathrm{~mm}$ from the injector nozzle, in ambient conditions
The variation in average droplet size seen across the working dosing range of the air-assist injectors further suggests that a single droplet size distribution may not accurately describe the sprays for modelling purposes. It should also be noted that PDI is incapable of resolving the size of non-spherical droplets and therefore any liquid jets passing through the measurement point are rejected by processing filters. Therefore the measured SMD values ignore the ligaments seen in Figure 10, suggesting the PDI results give a favourable representation of some sprays at high dosing rates.

\section{Radial Droplet Distribution}

As dosing systems are required to deliver DEF at higher dosing rates an understanding of the spray droplet distribution will be desirable for the design of other components within the system. Achieving NOx reduction efficiencies approaching $98 \%$ may even require a specified droplet distribution to provide the optimal spray for a deposit free system. To investigate current spray patterns the radial droplet distribution of the three wall mounted systems were captured in ambient conditions using LSI.

To illustrate the droplet distribution an RMS average of all of the images of an injection event was generated for each spray. Presented in Figure 12, A and $\mathrm{C}$ are both solid cone sprays with the majority of the droplets distributed within the centre of the spray; however, the wider cone angle of spray $\mathrm{C}$ resulted in a greater coverage within the exhaust section. An area of fine droplets can also be seen central to spray B; however the three jets are also visible as dense regions of the spray surrounding this.

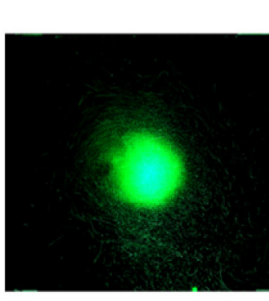

Spray A

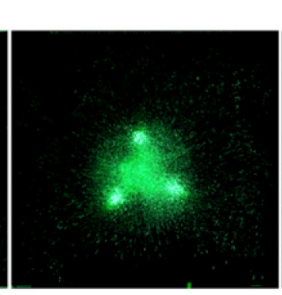

Spray B

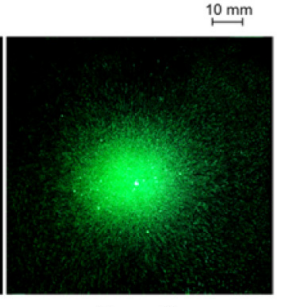

Spray C
Figure 12. RMS averaged laser sheet images of spray cross section at $50 \mathrm{~mm}$ from injector nozzle: DEF dosing at $1000 \mathrm{~g} \cdot \mathrm{hr}^{-1}$ in ambient conditions

To further analyse the droplet distributions and determine where the majority of injection fluid occurs for each spray the droplet size data collected during ambient PDI measurements has been used to generate the 2-D mass flux maps presented in Figure 13. Due to a finite sample grid and filtering processes the total calculated mass flux values were found to be below the actual dosing rate. To ensure comparable results all data sets have been normalised to give representative mass flux values at a dosing rate of $1000 \mathrm{~g} \cdot \mathrm{hr}^{-1}$. Sprays $\mathrm{A}$ and $\mathrm{C}$ show a Gaussian distribution of mass, with the centre of the spray containing the majority of droplets, although spray $\mathrm{C}$ is clearly more evenly dispersed over a wider cone. A single jet of spray D was used when collecting PDI measurements, thus a relatively low mass flux is seen across a small profile. A near Gaussian mass flux distribution is seen, although the majority of mass from the spray occurs away from the centre of the orifice. Larger droplets formed through liquid film shearing as the flow is turned through $90^{\circ}$ at the orifice may explain this result. A distinct distribution of mass flux is seen in the results of spray B, with the majority of mass concentrated 
within the three jets of the spray and an even mass flux across the rest of the spray profile. The results show that the choice of spray strategy does have a dramatic impact on how the DEF spray will be dispersed within the exhaust, highlighting how influential knowledge of spray structure could be during the SCR system design phase.

The mass flux maps illustrate that the spray structures vary significantly between the dosing strategies; however, as the behaviour of the spray within a flow will be influenced by the mass and velocity of the droplets, momentum is considered to be another important attribute of the spray. PDI measurements of droplets size and velocity are collected simultaneously and linked within the data set; therefore, it has been possible to calculate average droplet momentum at each measurement point. Although momentum is a vector quantity the averaged values shown in Figure 14 have been calculated using a single component of droplet velocity, in the direction of the axis of the spray. Points on the illustrations that are white indicate measurement points at which no droplets were detected, suggesting the boarder of the spray.
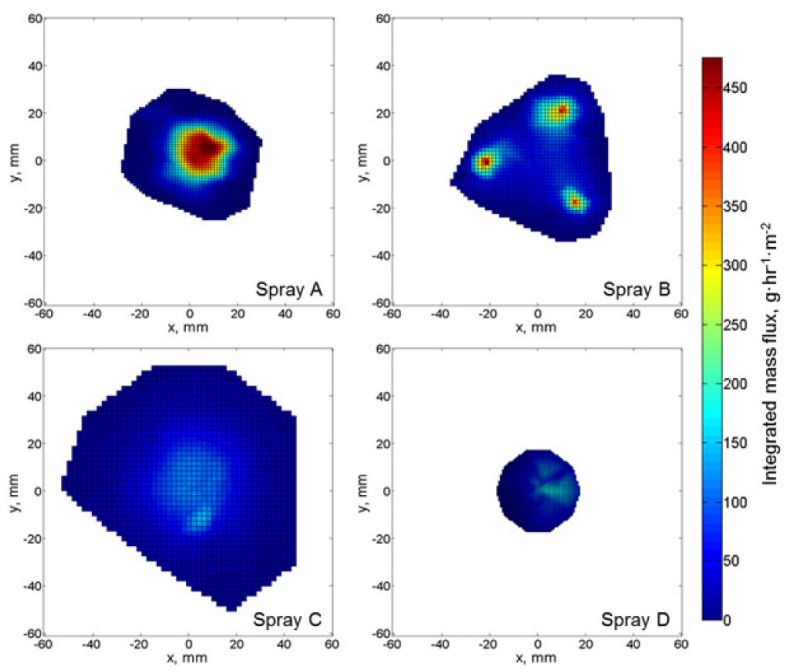

Figure 13. 2-D colour maps of spray mass flux at a plane $100 \mathrm{~mm}$ from the injector nozzle: DEF dosing at $1000 \mathrm{~g} \cdot \mathrm{hr}^{-1}$ in ambient conditions
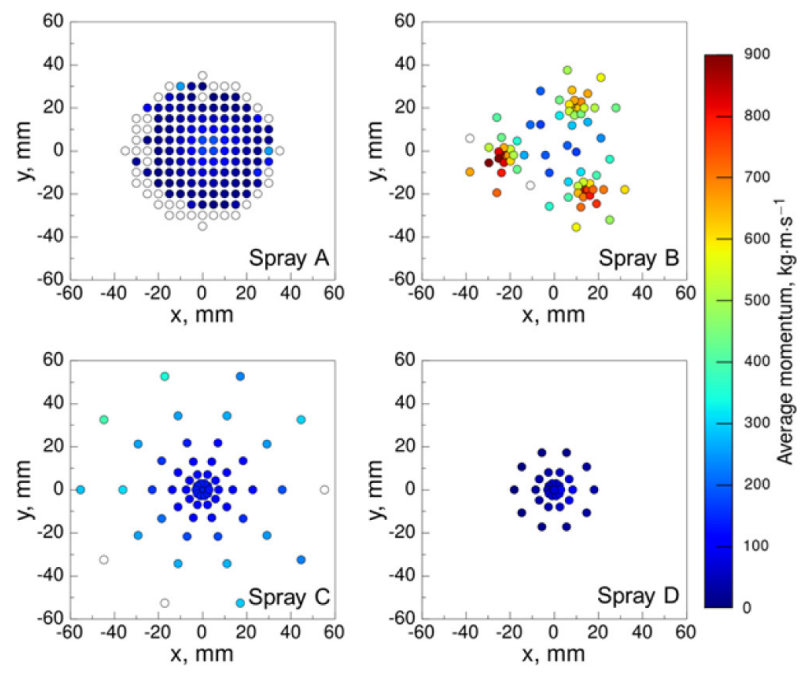

Figure 14. 2-D colour maps of average droplet momentum at a plane $100 \mathrm{~mm}$ from the injector nozzle: DEF dosing at $1000 \mathrm{~g} \cdot \mathrm{hr}^{-1}$ in ambient conditions
The illustration of average droplet momentum gives further insight into the variation in spray structure achieved by the different injection strategies. The most obvious result is the difference in magnitude between the momentum of spray B and that of the other sprays. The larger droplets within the three jets of the spray showed a significantly higher momentum than the finer sprays produced by the other systems, suggesting the strategy will result in different droplet interactions within exhaust flows. Other notable observations include the variation in momentum across spray $\mathrm{C}$, which results suggest produced higher momentum droplets around the edge of the spray. The two air-assisted sprays displayed a similar distribution of low momentum droplets. In the case of spray D such a distribution is likely to be desirable to ensure droplets are quickly entrained in the flow given the reduced distance between the orifice and internal surfaces of the exhaust.

\section{Droplet Interactions with Exhaust Flows}

To understand how spray structure translates to behaviour within a real-world SCR system each of the injectors were installed on the optical test section and observations of droplet interactions within generated flows were made. Laser sheet images were captured to identify the distribution of droplets within the optical test section as the spray developed and are used to demonstrate the effect that temperature and flow rate have on the different spray structures. Shadowgraphy images of the injection event are then presented to show the resistance the spray structures show to the bulk flow.

\section{Spray Distributions in Flow}

No mixing devices were used during this study; however laser sheet images at a plane $100 \mathrm{~mm}$ from the point of injection were taken to identify the spray distribution within the flow at a typical location of a mixer inlet, thus indicating the coverage each strategy would give.

Flow configuration and injector location have been given in Figure 15 which depicts a typical shadowgraphy image of the injection event into a hot-flow, as well as illustrating how the spray is deflected by the bulk flow. The full equipment set-up was previously illustrated in Figure 4.

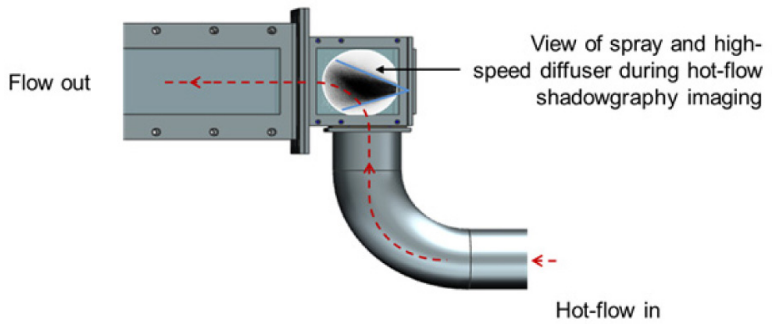

Figure 15. Illustration of configuration used during hot-flow shadowgraphy imaging of spray deflection

Hot-flow laser sheet imaging has shown that the mass flow rate of bulk gas had a dramatic effect on the distribution of droplets within the test section, while the impact of temperature appears to be minor. This effect was seen most strongly in the droplet distributions of spray A, presented in Figure 16. The shift towards the upper half of the test section is clear at all conditions, demonstrating that the fine droplets were quickly entrained within the bulk flow; however, 
similar droplet distributions at low and high temperature conditions demonstrates that flow temperature does not noticeably effect interactions between the droplets and the flow.

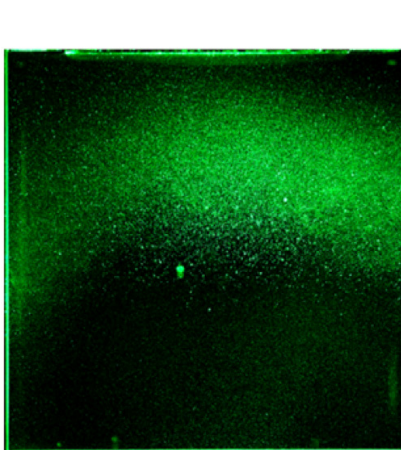

$200{ }^{\circ} \mathrm{C}, 900 \mathrm{~kg} \cdot \mathrm{hr}^{-1}$

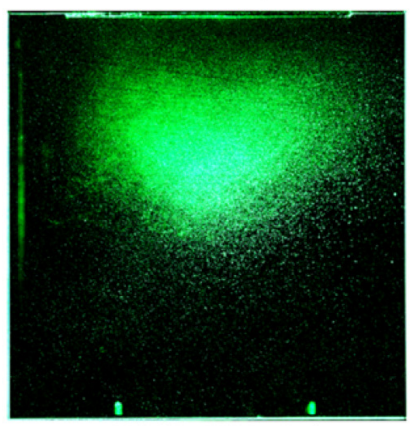

$200{ }^{\circ} \mathrm{C}, 200 \mathrm{~kg} \cdot \mathrm{hr}^{-1}$

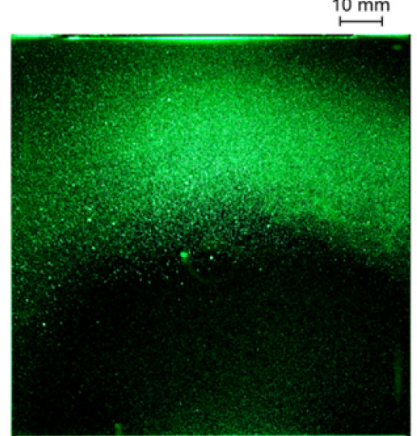

$350{ }^{\circ} \mathrm{C}, 900 \mathrm{~kg} \cdot \mathrm{hr}^{-}$

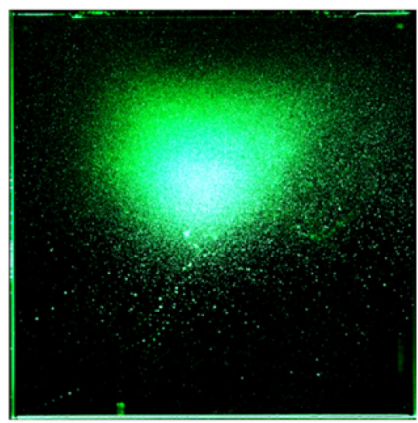

$350{ }^{\circ} \mathrm{C}, 200 \mathrm{~kg} \cdot \mathrm{hr}^{-1}$
Figure 16. RMS averaged laser sheet images of the droplet distribution of spray A at all hot-flow conditions at $100 \mathrm{~mm}$ from the injector nozzle

At high gas flow rates the distribution is noticeably different from that seen at the low flow rate condition, indicating that the gas mass flow rate has a significant impact on spray distribution. A reduction in the spray quantity passing through the plane at the high flow rate suggests that a large portion of the spray had impacted on the top surface of the test section before reaching the image plane, presenting a possible mechanism for internal deposit formation.

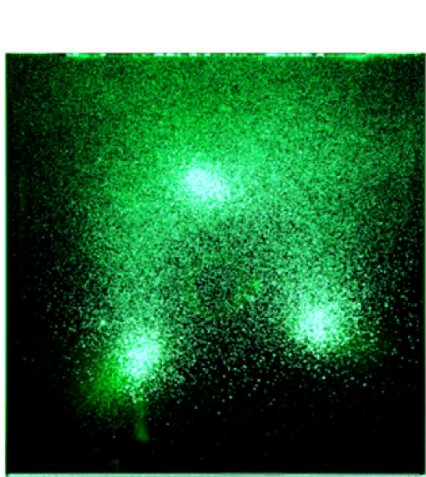

$350{ }^{\circ} \mathrm{C}, 200 \mathrm{~kg} \cdot \mathrm{hr}^{-1}$

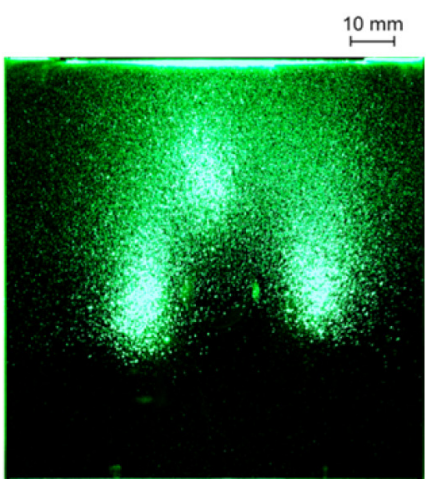

$350{ }^{\circ} \mathrm{C}, 900 \mathrm{~kg} \cdot \mathrm{hr}^{-1}$
Figure 17. RMS averaged laser sheet images of the droplet distribution of spray B with changing gas flow rate, taken $100 \mathrm{~mm}$ from the injector nozzle

In contrast the imaged droplet distributions in Figure 17 indicate that spray B is less susceptible to deflection from the bulk gas flow. Some entrainment of the lower momentum droplets within the centre of the spray can be seen; however, the three jets show resistance to flow deflection and as a result a consistent droplet distribution at the plane was achieved. A mixer location $100 \mathrm{~mm}$ from the nozzle is therefore likely to be an acceptable location for this strategy given the spray has been able to diverge without significant wall impingement.

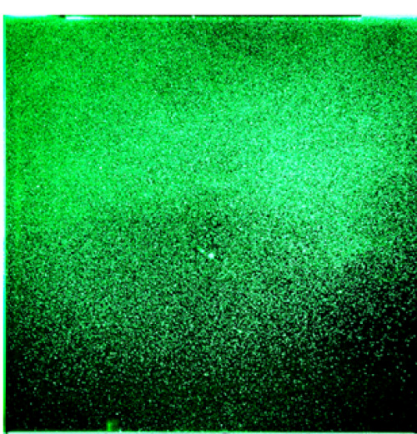

$350{ }^{\circ} \mathrm{C}, 200 \mathrm{~kg} \cdot \mathrm{hr}^{-1}$

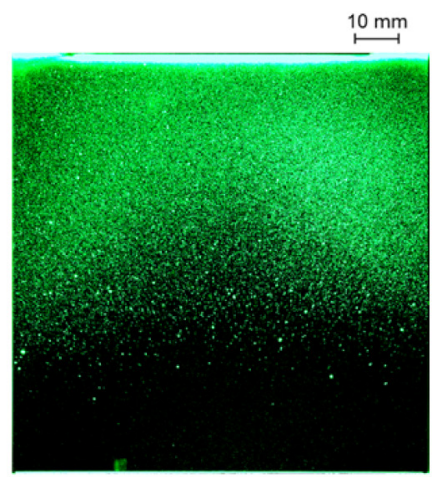

$350{ }^{\circ} \mathrm{C}, 900 \mathrm{~kg} \cdot \mathrm{hr}^{-1}$
Figure 18. RMS averaged laser sheet images of the droplet distribution of spray $\mathrm{C}$ with changing gas flow rate, taken $100 \mathrm{~mm}$ from the injector nozzle

At low gas flow rates the spray produced by system $\mathrm{C}$ diverged to cover the majority of the test section, as shown in Figure 18. Some deflection at high flows was seen as a bias towards the top of the section; however, the quantity of droplets detected at the plane suggests that the spray has some resistance to deflection from the bulk flow. Spray-wall impingement was seen before the measurement plane, caused by deflection and the large cone angle of the spray; prevention of impaction would therefore require a mixer within 100 $\mathrm{mm}$ of the injector.

As system D was installed in a different configuration to the other injection systems the laser sheet images of the droplet distribution were taken at a plane $5 \mathrm{~mm}$ downstream of the nozzle. Shown in Figure 19, they indicate that the penetration of the radial spray was not significantly altered by the bulk flow rate, with similar radial penetration seen at all test conditions. A reasonable coverage of the test section was achieved by the injector due to the radial nature of the spray; however, despite good spray atomisation it appears that the droplets were too large to become entrained in the flow before impacting on the internal surfaces of the test section, which may lead to deposit formation at the increased DEF delivery rates required in high efficiency SCR systems.

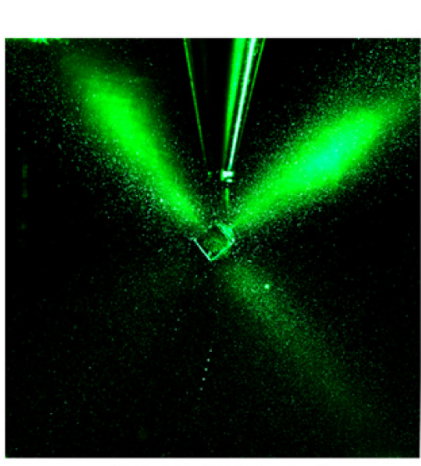

$350{ }^{\circ} \mathrm{C}, 200 \mathrm{~kg} \cdot \mathrm{hr}^{-1}$

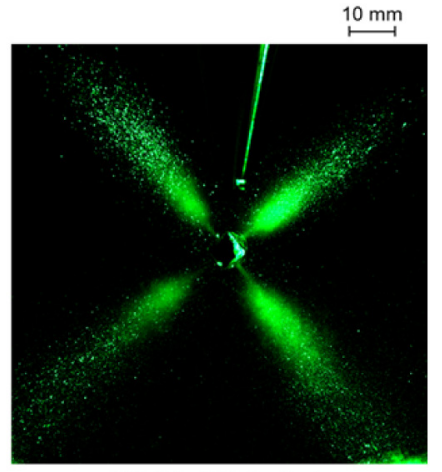

$350{ }^{\circ} \mathrm{C}, 900 \mathrm{~kg} \cdot \mathrm{hr}^{-1}$
Figure 19. RMS averaged laser sheet images of the droplet distribution of spray D with changing gas flow rate, taken $5 \mathrm{~mm}$ from the injector nozzle 
Observations of further spray development within the flow were made at a plane $400 \mathrm{~mm}$ downstream of the point of injection. At this distance more even droplet distributions were seen for all sprays; however, the number of droplets still present varied noticeably between the systems. Figure 20 indicates that the jets produced by spray B developed within the flow resulting in a large quantity of spray present downstream. This may be due either to the larger size of droplets produced by the injector or the resistance to deflection shown by the spray; however, considering sprays A and C consist of similarly sized droplets the low image intensity of spray A suggests that wall impingement due to deflection was the more significant cause of reduction in droplets as the spray developed.

Although dependent on the distance to the SCR catalyst, the results also suggest that relying on free stream evaporation alone may result in droplets present in the flow at the catalyst face, offering support for the observation that a significant level of urea slip may occur in some systems [므].

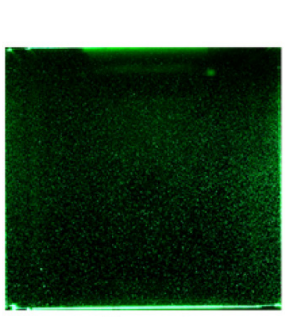

Spray A

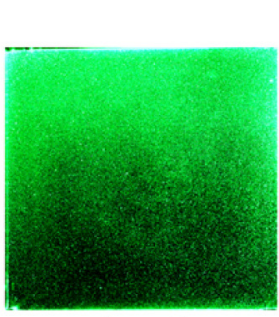

Spray B

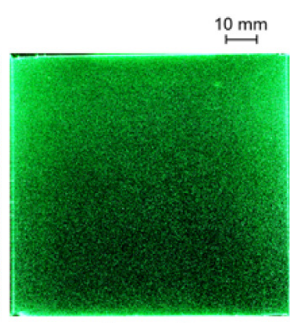

Spray C
Figure 20. RMS laser sheet images of droplet distribution of wall mounted sprays $400 \mathrm{~mm}$ from the point of injection at $350^{\circ} \mathrm{C}, 900 \mathrm{~kg} \cdot \mathrm{hr}^{-1}$

\section{Spray Deflection}

Visualising the injection event within hot-flows was achieved using shadowgraphy, allowing observation of how each spray interacts with the bulk gas flow at the point of injection.

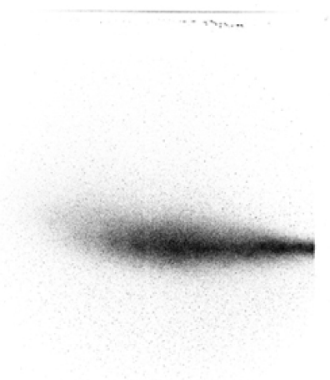

$350{ }^{\circ} \mathrm{C}, 200 \mathrm{~kg} \cdot \mathrm{hr}^{-1}$

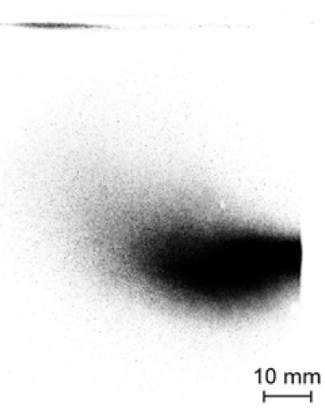

$350{ }^{\circ} \mathrm{C}, 900 \mathrm{~kg} \cdot \mathrm{hr}^{-1}$
Figure 21. RMS averaged shadowgraphy images of spray A corner injection event

As before, the sprays were more susceptible to changes in gas flow rate than temperature. Figure 21 shows the fairly regular structure of spray A at the low flow conditions, and the deflection caused by an increase in flow rate. The spray deflection was seen to fluctuate substantially during the injection event, indicating that the droplets were easily entrained in the unstable gas flow. Results from the spray $\mathrm{B}$ injection event are shown in Figure 22. The structure of the spray is clearly less affected by the change in flow rate than spray A, with the spray jets, which contained the bulk of the injected mass, remaining consistent at both conditions. This is in agreement with the deflection inferred from laser sheet images, and supports the observation that the higher momentum jets are more resistant to the bulk flow, resulting in a more consistent droplet distribution as the gas flow rate changes.

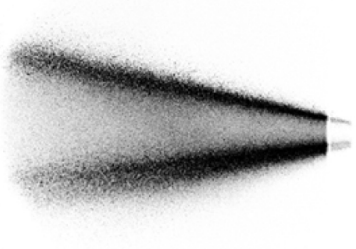

$350^{\circ} \mathrm{C}, 200 \mathrm{~kg} \cdot \mathrm{hr}^{-1}$

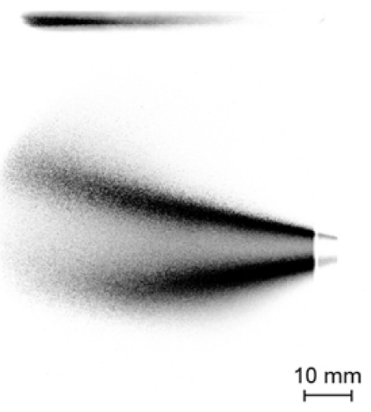

$350{ }^{\circ} \mathrm{C}, 900 \mathrm{~kg} \cdot \mathrm{hr} r^{-1}$
Figure 22. RMS averaged shadowgraphy images of spray B corner injection event

As fluctuations in the spray cannot be captured in the summary images above an attempt to quantify the susceptibility to flow deflection has been made by processing the image series and extracting the spray angle in each frame. Although not a direct measure of droplet entrainment the average spray angle gives an indication of spray deflection while the range shows the extent the spray structure fluctuates across the injection event. Data in $\underline{\text { Table } 3}$ summarises the results, illustrating both the large amount of fluctuation seen in spray A and the resistance of spray B to deflection.

Table 3. Statistical results from spray angle detection during corner injection events at $350^{\circ} \mathrm{C}, 900 \mathrm{~kg} \cdot \mathrm{hr}^{-1}$

\begin{tabular}{|l|c|c|c|}
\hline & Spray A & Spray B & Spray C \\
\hline Average angle $\left(^{\circ}\right.$ ) & 45 & 32 & 49 \\
\hline Deflection range $\left(^{\circ}\right.$ ) & 44 & 16 & 28 \\
\hline Standard deviation $\left(^{\circ}\right)$ & 8.1 & 2.7 & 4.7 \\
\hline
\end{tabular}

\section{Discussion}

The characterisation of four dosing systems has shown that a diverse range of injection strategies can be used to achieve DEF delivery for SCR applications; however, throughout testing several notable observations about the strategies were made and are summarised below.

Firstly, the range of variation in spray structure seen during testing has shown that an understanding of the dosing strategy being used is critical before any system design can be completed. A detailed characterisation of the spray would be encouraged given the observation of features such as the initial fluid slug in spray $\mathrm{C}$, which present the potential to cause deposit formation unless mitigated with design. 
When injecting into a hot-flow a link between droplet momentum and spray deflection was seen, with high momentum sprays showing reduced flow biasing to give a more consistent spray distribution across operating conditions. Although achieved at the cost of spray atomisation, the high momentum spray of system B has shown the most resistance to flow biasing and therefore may be desirable in constrained system architectures. Removing the issue of flow biasing with a centre-line injection strategy presents an interesting approach; however, ensuring the spray is sufficiently atomised to entrain in the gas flow before impinging on internal surfaces is essential to reduce the chance of deposit formation. Wall injection on a straight pipe is an alternative approach which has not been considered within this study, although it presents the potential to provide a robust dosing strategy. If adopted, similar consideration should be given to the effect of mass flow rate on spray distribution within the gas flow and an appropriate dosing strategy should be identified to mitigate spraywall impingement while maintaining high uniformity across the exhaust.

The presence of droplets within the gas phase $400 \mathrm{~mm}$ downstream of the point of injection, and the loss of droplets through spray-wall impingement shortly after injection support the use of an additional component such as a mixing device, either to assist in atomisation or contain the spray, depending on dosing strategy. The design of mixer geometry should therefore consider the structure of spray being used, as should the location of the mixer relative to the point of injection. Knowing the spray structure and behaviour within the flow enables optimal positioning of the mixer to ensure high spray coverage while minimising any spray-wall impingement before the mixer front face.

With inevitable variation in exhaust architecture the choice of dosing strategy should be reasoned on an individual basis; however, knowledge of the dosing strategy selected and an understanding of how the spray interacts with the exhaust flow provides designers with the fundamental information needed to develop optimised systems with the potential to meet the higher dosing rates now demanded.

\section{CONCLUSIONS}

This paper has presented detailed experimental characterisation of a range of production urea SCR dosing systems, in both ambient conditions and within hot gas flows representative of real-world application.

The differences in spray structure between the strategies have been shown to be substantial, with a range of $82 \mu \mathrm{m}$ seen across the Sauter mean diameters of the sprays. Radial mass flux distributions show further differences between the sprays, with a striking variation seen in the distribution of droplets across the four systems. Average droplet momentum has also been shown to vary across each spray profile and between all systems, presenting a strong case for detailed spray characterisation to be performed before dosing strategy selection.

Variations in spray structure across the operating dosing ranges have also been demonstrated, particularly in strategies using a second fluid to assist in droplet atomisation. With an increase in SMD of up to 141 $\%$ across the range of dosing rates tested, the sensitivity of design tools such as CFD to changes in the spray droplet distribution should be considered to ensure that modelling results are representative across the operating range of the injection system used.

Observation of the interaction between the sprays produced and the bulk hot-flow has revealed that the strategy used to inject DEF has a significant impact on spray deflection, droplet distribution, and spray-wall impingement within the system. In particular, gas mass flow rate largely dictates the distribution of fine droplets within the flow. The flow biasing effect is seen to be reduced for sprays consisting of higher momentum droplets, therefore a more consistent coverage of the pipe across a wider range of flow conditions can be maintained at the cost of spray atomisation. An injection system capable of producing a high momentum spray with uniformly distributed mass would therefore provide a more optimal droplet distribution within the flow. PDI data has shown that urea injection systems capable of producing a uniform spray distribution already exist; designing the exhaust geometry to accommodate the spray and maintain uniformity should therefore be considered as a path to developing high efficiency SCR systems.

As increasing engine out NOx levels demand higher DEF delivery rates it is likely SCR dosing systems will need to fully utilise the surface area of a mixing device to prevent localised cooling and deposit formation. Results have shown that maintaining a well atomised, uniformly distributed spray across changing exhaust conditions presents a significant challenge. A holistic design approach will be critical in achieving optimised systems; with a detailed understanding of the spray strategy employed essential before a design can be optimised. Further study will aim to investigate the utilisation of mixers, applying knowledge of the DEF sprays to the design of an SCR system capable of stable operation within the aftertreatment system of high NOx engines.

\section{REFERENCES}

1. Koebel, M., Elsener, M., and Kleemann, M., "Urea-SCR: A Promising Technique to Reduce NOx Emissions from Automotive Diesel Engines," Catalysis Today 59(3-4):335-345, 2000, doi:10.1016/S09205861(00)00299-6.

2. Koebel, M. Elsener, M., and Marti, T., "NO X -Reduction in Diesel Exhaust Gas with Urea and Selective Catalytic Reduction," Combustion Science and Technology 121(1-6):85-102, 1996, doi:10.1080/00102209608935588.

3. Munnannur, A., Chiruta, M., and Liu, Z., "Thermal and Fluid Dynamic Considerations in Aftertreatment System Design for SCR Solid Deposit Mitigation,” SAE Technical Paper 2012-01-1287, 2012, doi:10.4271/2012-01-1287.

4. Zheng, G., Fila, A., Kotrba, A., and Floyd, R., "Investigation of Urea Deposits in Urea SCR Systems for Medium and Heavy Duty Trucks," SAE Technical Paper 2010-01-1941, 2010, doi:10.4271/2010-01-1941.

5. Smith, H., Lauer, T., Mayer, M., and Pierson, S., "Optical and Numerical Investigations on the Mechanisms of Deposit Formation in SCR Systems," SAE Int. J. Fuels Lubr. 7(2):525-542, 2014, doi:10.4271/2014$\underline{01-1563}$.

6. De Rudder, K., "Tier 4 High Efficiency SCR for Agricultural Applications," SAE Int. J. Commer. Veh. 5(1):386-394, 2012, doi:10.4271/2012-01-1087.

7. Schaber, P. M., Colson, J., Higgins, S., Thielen, D., et al., "Thermal Decomposition (pyrolysis) of Urea in an Open Reaction Vessel," Thermochimica Acta 424(1-2): 131-142, 2004, doi:10.1016/j. tca.2004.05.018.

8. Fang, H.L., and DaCosta, H.F.M., "Urea Thermolysis and NOx Reduction with and without SCR Catalysts," Applied Catalysis B: Environmental 46(1):17-34, 2003, doi:10.1016/S0926-3373(03)00177-2. 
9. Bernhard, A.M., Peitz, D., Elsener, M., Wokaun, A., et al., "Hydrolysis and Thermolysis of Urea and Its Decomposition Byproducts Biuret, Cyanuric Acid and Melamine over Anatase TiO2," Applied Catalysis B: Environmental 115-116:129-137, 2012, doi:10.1016/j. apcatb.2011.12.013.

10. Hüthwohl, G. and Dolenec, S., "A new Approach in AdBlue Dosing to Improve Performance and Durability of SCR Systems for the Use in Passenger Cars up to Heavy Duty Vehicles," SAE Technical Paper 201101-2095, 2011, doi: 10.4271/2011-01-2095.

11. Maass, J, Eppler, A., Scholz, J., Gentgen, H., et al., "Influences of Adblue Spray Targeting and Mixing Devices on the UWS Distribution Upstream of the SCR Catalyst," IMechE Fuel Systems for IC Engines, 21-41, 2012, doi:10.1533/9780857096043.2.21

12. Kawauchi, S., and Takagi, M., "Study of Spray Distribution and Evaporation and Thermolysis Processes of Reductant in Urea SCR," Marine Engineering, 46(4):620-625, 2011, doi:10.5988/jime.46.620

13. Nova, I., and Tronconi, E., "Urea-SCR Technology for deNOx After Treatment of Diesel Exhausts," (Fundamental and Applied Catalysts, Springer), 12-13, doi:10.1007/978-1-4899-8071-7 1.

14. Zheng, G., Palmer, G., Salanta, G., and Kotrba, A., "Mixer Development for Urea SCR Applications," SAE Technical Paper 2009-01-2879, 2009, doi:10.4271/2009-01-2879.

15. Gardner, T., Sampath, M., Zheng, G., Kotrba, A. et al., "Evaluation of Mixer Designs for Large Diesel Exhaust Aftertreatment Systems," SAE Technical Paper 2010-01-1943, 2010, doi:10.4271/2010-01-1943.

16. Alano, E., Jean, E., Perrot, Y., Brunel, J. et al., "Compact SCR for Passenger Cars," SAE Technical Paper 2011-01-1318, 2011, doi: 10.4271/2011-01-1318.

17. Held, W., Emmerling, G., Döring, A., Richter, K., et al., "Catalyst Technologies for Heavy-Duty Commercial Vehicles Following the Introduction of EU VI and US2010; The Challenges of Nitrogen Oxide and Particulate Matter Reduction for Future Engines," 28th International Vienna Motor Symposium, 2007

18. Stanton, D., Charlton, S., and Vajapeyazula, P., "Diesel Engine Technologies Enabling Powertrain Optimization to Meet U.S. Greenhouse Gas Emissions," SAE Int. J. Engines 6(3):1757-1770, 2013, doi:10.4271/2013-24-0094.

19. Johnson, T., "Vehicular Emissions in Review," SAE Int. J. Engines 5(2):216-234, 2012, doi:10.4271/2012-01-0368.

20. Benjamin, S. F., Gall, M., and Roberts, C. A., "Conversion of Nitric Oxide in an Engine Exhaust by Selective Catalytic Reduction with a Urea Spray under Steady-State and Transient Engine-Load Conditions," Proc IMechE Part D: J. Automobile Engineering 228 (7) :758-770, 2014 doi: $10.1177 / 0954407013511443$.

\section{CONTACT INFORMATION}

\section{Paul Gaynor}

Wolfson School of Mechanical and Manufacturing Engineering

Loughborough University

LE11 3TU UK

P.D.Gaynor@,1boro.ac.uk

\section{ACKNOWLEDGMENTS}

The authors would like to acknowledge the Energy Technologies Institute (ETI) for the financial support that has enabled this work to be completed. Thanks must also go to the technical staff at Loughborough University; their help provided since the start of the project has been greatly appreciated. Finally gratitude is extended to project partners Caterpillar and Johnson Matthey PLC, notably Ron Silver, Dave Heaton, Mark Kennedy and Michael Nash.

\section{DEFINITIONS/Abbreviations}
ASC - ammonia slip catalyst
CAN - control area network
CFD - computational fluid dynamics
DEF - diesel exhaust fluid
HD - heavy duty
HNCO - isocyanic acid
LSI - laser sheet imaging
NOx - oxides of nitrogen
$\mathbf{N H}_{3}$ - ammonia
PDI - phase Doppler interferometry
RMS - root mean square
SCR - selective catalytic reduction
SMD - Sauter mean diameter

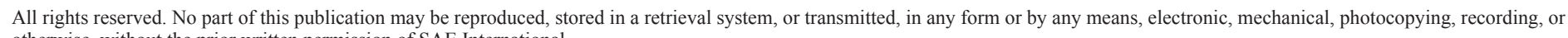
otherwise, without the prior written permission of SAE International. 